\title{
ATENÇÃO, ESTUDO E TECNOLOGIA
}

Adriano Rodrigues Ruiz

Docente do Mestrado em Educação da UNOEST

\section{RESUMO}

Este artigo relata pesquisa de natureza bibliográfica que busca compreender, no mundo educacional, a teia que envolve o conhecimento que o aluno tem de si próprio como aprendiz; a natureza emancipatória da competência para tomar boas decisões ao estudar; o contexto tecnológico vivido que favorece uma forma de atenção que passeia por muitos focos. Ao caminhar por essas paisagens, depreendemos a importância da percepção que o aprendiz possui de suas próprias competências e do controle pessoal que exerce sobre as atividades escolares; a necessidade de restituir ao estudo a função de coração de toda atividade educativa; o desafio de produzir relações entre estudantes e estudo mais ligadas ao pensamento que às tarefas. Renovar a política cognitiva requer a superação da cultura que privilegia tarefas predefinidas e a solução de problemas dados, abrindo espaço para invenção de problemas e de mundos.

Palavras-chave: Aprender a estudar, autoconhecimento, atenção, contexto tecnológico.

\section{INTRODUÇÃO}

As TIC povoam um amplo espectro das discussões, ora como ricas fontes de possibilidades e ora como mensageiras de desvios preocupantes. Por isso, neste estudo partimos da premissa que vivemos um momento interessante para a renovação das reflexões educacionais.

Nesta pesquisa bibliográfica, direcionamos nosso olhar para duas compreensões acerca do contexto cognitivo que estamos a viver, a primeira anuncia largas possibilidades, sustentadas pela colaboração cognitiva e a segunda aponta severos e perigosos obstáculos, com um determinado enfraquecimento das posturas reflexivas a partir daquilo que Turcke (2010) chama de sociedade excitada, que se caracteriza pela distração concentrada.

Tendo por referência o quadro apontado, colocamos a arte de estudar como objeto de reflexão, entendemos ser oportuno ressignificá-la, pois, ainda quase todas as reverências são voltadas ao ensino amparado pela transmissão. Porém, imerso em um mundo em que a disponibilidade de informações é ampla, o modelo instrucionista dá claros sinais de esgotamento, aí emerge o saber estudar com a aura emancipatória, como abertura à aprendizagem autorregulada, que permite aos estudantes comportamentos cognitivos autônomos e conscientes. Nesse trilhar, o autoconhecimento surge como sustentáculo na formação de pessoas com bom domínio de estratégias de estudo. 


\section{METACOGNIÇAO COMO AUTOCONHECIMENTO}

O autoconhecimento abre caminhos para que pessoas façam as melhores opções quando o assunto for traçar trajetórias de aprendizagem. Silva e Sá (1993, p. 31) dizem que os sujeitos constroem teorias implícitas acerca de si mesmos sobre a inteligência. Essas teorias tendem a orientar as pessoas, quando acreditam ser a "inteligência é um traço fixo tendem a orientar-se para obter avaliações favoráveis desse traço", buscando resultados; já as que acreditam que "a inteligência uma qualidade maleável tendem a orientar-se para desenvolver essa qualidade", adotando objetivos de aprendizagem.

Para isso, é importante que os estudantes compreendam ser a inteligência uma construção conduzida por eles próprios. Rosário e Almeida (2005, p. 144) enfatizam que a aprendizagem precisa significar "a apropriação de mecanismos de busca e selecção de informação, assim como de processos de análise e resolução de problemas, que viabilizem a autonomia progressiva do aluno no aprender e no realizar, os quais se prolongam por toda a vida."

Cosenza e Guerra (2011, p. 98) explicam que as funções executivas são responsáveis pela regulação cotidiana ao possibilitarem "nossa interação com o mundo frente às mais variadas situações que encontramos. Por meio delas organizamos nosso pensamento, levando em conta as experiências e conhecimentos armazenados em nossa memória". Em domínios escolares, elas "devem estar voltadas para que os estudantes aprendam a planejar suas atividades, sendo capazes de estabelecer metas".

O que é necessário é que os alunos "saibam não somente procurar informação utilizando os recursos existentes, mas que saibam, também, identificar as questões relevantes, fazendo inferências e generalizações". Na atualidade, "nem sempre há um ambiente estruturado de forma adequada para o desenvolvimento das funções executivas. Esse é um problema que deveria ser levado em conta se quisermos realmente educar nossos jovens para uma vida útil e feliz (COSENZA; GUERRA, 2011, p. 98).

Alvares e Klimenko (2009) asseguram que as praticas de ensino dedicadas a fomentar a aprendizagem autorregulada consideram três funções do ensino: formar pensadores flexíveis, autônomos e com sentido crítico; desenvolver as habilidades cognitivas e metacognitivas nos estudantes, para que adquiram o senso para orientar-se, buscar, organizar e compreender a informação; partir da concepção do conhecimento como algo flexível, pertinente e argumentado.

Cosenza e Guerra (2011) destacam que o cérebro sempre esta disposto a processar o que percebe como significante e gratificante, por isso é importante exercer controle sobre a 
quantidade e a qualidade do que queremos ou devemos processar. Isso é compatível com a perspectiva colocada por Khan (2013, p. 50) ao assegurar que "aprendemos, antes de tudo, decidindo aprender, assumindo compromisso com a aprendizagem, que, por sua vez, gera concentração."

Silva e Sá (1993, p. 64) argumentam que o aluno exerce papel ativo na própria aprendizagem se tiver um objetivo - fruto de uma construção pessoal - por ele valorizado, "que o levará a despender esforços e a persistir nas tarefas". Essas pesquisadoras esclarecem que desenvolver hábitos de estudo objetiva "possibilitar ao estudante o acesso a condições e instrumentos mentais, que Ihe permitam tornar a aprendizagem escolar mais efetiva e autônoma" (SILVA; SÁ,1993, p. 71).

Silva e Sá (1993, p. 32) asseveram ser necessário "que o sujeito se veja como um agente activo para pôr em marcha os processos cognitivos necessários a um bom desempenho". Nessa perspectiva, a motivação para aprender depende, também, da percepção que o aprendiz possui de suas próprias competências e do controle pessoal "que acredita exercer sobre as actividades escolares".

Almeida (2002) alerta que temos uma escola ainda pouca apta para intervir e "ajudar os alunos a estudar, a aprender e a pensar". Esse autor revela acreditar que "a crença atual na modificabilidade cognitiva e a consciência reinante de que a escola deve se preocupar com o ensinar a aprender e a pensar acabarão por introduzir mudanças significativas na lógica funcional e nas práticas escolares".

Em síntese, aprender a estudar implica a tomada de consciência que cabe a cada pessoa a responsabilidade de sua construção como aprendiz autônomo e competente. Contudo, a escola parece ainda renitente quanto a delegar aos alunos espaço de protagonismo.

\section{Estudo é assunto importante}

Aprender a estudar tem natureza emancipatória, pois abre portas ao autogoverno, quebrando a velha lógica que sustenta a educação regulada pelo professor e pouco favorável à autonomia dos alunos.

Chevallard, Bosch e Gascón (2001, p. IX) apontam o estudo como elo perdido entre ensino e aprendizagem, disso decorrendo a crença em aprendizagem quase imediata gerada pelas atividades de ensino. $O$ estudo sucumbe em um contexto dominado pelo ensino "que parece querer controlar todo o processo didático e uma aprendizagem cada vez mais frágil pela exigência de que seja produzida como consequência imediata, quase instantânea, do ensino". O desafio colocado por 
esses autores "é restituir ao estudo o lugar que lhe é devido: o coração do projeto educativo de nossa sociedade".

Nessa linha de raciocínio, "em vez de limitar a educação à interação entre ensino e aprendizagem, propomos considerá-la de maneira mais ampla, como um projeto de estudo cujos principais protagonistas são os alunos" (CHEVALLARD, BOSCH e GASCÓN, 2001, p. IX). Caberia ao professor coordenar o estudo, aos alunos estudar e aos pais ajudar os filhos a estudar e encontrarem sentido ao esforço que lhe é exigido.

Com o estudo no centro do processo, para esses autores, restabeleceríamos a comunicação "entre alunos, pais e professores, fazendo com que o diálogo entre sociedade e escola recupere seu sentido primordial: a escola leva as novas gerações a estudar aquelas obras humanas que melhor lhes servirão para compreender a sociedade na qual estão dispostas a entrar."

Silva e Sá (1993, p. 71) asseveram que "desenvolver hábitos e estratégias de estudo tem por objetivo final possibilitar ao estudante o acesso a condições e instrumentos mentais, que lhe permitam tornar a sua aprendizagem escolar mais efectiva e autónoma", nesse processo objetiva-se desenvolver competências cognitivas que possibilitem ao estudante maior controle "na realização das suas tarefas escolares. Ao mesmo tempo, procura-se proporcionar o desenvolvimento de sentimentos mais positivos face ao estudo, aumentando os sentimentos de eficácia pessoal e de motivação para a aprendizagem."

Figueiredo e Barros (sd) afirmam que para "aprender verdadeiramente é preciso antes de mais saber aprender! Saber aprender exige muito do conhecimento e reflexão sobre as nossas cognições - metacognição." Esses autores escreveram que em uma perspectiva sócio-cognitiva, a autorregulação é entendida como um processo conduzido pelos próprios aprendizes que transformam suas capacidades mentais em competências acadêmicas.

Pinto (2001) afirma que, sob o olhar cognitivo, a aprendizagem é concebida em termos de aquisição de novas informações e a sua integração no conjunto de conhecimentos existentes. Aprender, porém, não se limita à aquisição de novas informações, mas implica a correção, ampliação e reorganização dos conhecimentos adquiridos anteriormente. Neste contexto, a aprendizagem não é independente dos outros processos mentais de atenção, percepção, memória e raciocínio, sendo o conhecimento de que somos portadores o resultado da mediação mais ou menos coordenada dos vários processos cognitivos.

Alvares e Klimenko (2009) esclarecem que a organização da atividade de estudo como processo reflexivo de solução de problemas, permite aos alunos a tomada de consciência da 
presença das habilidades e, também, da necessidade delas no processo de estudo e em situações cotidianas, isso favorece criar condições para o fortalecimento da motivação para buscar estas habilidades.

Essas autoras asseveram que a ideia de evolução cultural não se limita ao sucesso na obtenção de bons escores nas em avaliações escolares, implica avanços por horizontes desconhecidos e contribuições para a transformação cultural. Por sua vez, "essa evolução não se refere apenas ao progresso econômico, tecnológico ou científico da civilização, também abarca o desenvolvimento da dimensão do humano a partir do ser, pensar e atuar em relação consigo mesmo e com os demais".

Como esclarecem Jou e Sperb (2006), a metacognição é a capacidade do ser humano ter consciência de seus atos e pensamentos, de pensar o próprio pensar, de desenvolver estratégias para interagir com o meio. Por isso, o olhar atento à educação aberta ao estudo autodirigido possibilita o trânsito por um universo de autonomia com escolhas e significações.

\section{ESTUDAR NO CIBERESPAÇO}

As TIC trouxeram ao mundo escolar dois sentimentos não convergentes - o que parece ter sonoridade maior manifesta-se sobre a impaciência dos alunos e o outro fala de obstáculos oriundos de um conservadorismo quase que autista da cultura escolar e, ao mesmo tempo, de largas possibilidades de reinvenção dos caminhos da aprendizagem.

Transitando pelo campo que aponta a impaciência, encontramos Kastrup (2004) que assevera existir "na sociedade contemporânea um excesso de informação e uma velocidade acelerada que convoca uma mudança constante do foco da atenção, em função dos apelos que se multiplicam sem cessar".

Essa pesquisadora fala que o anseio pela novidade não permite o tempo requerido para experiências consistentes. Ela esclarece que a distração é um funcionamento em que a atenção vagueia, foge do foco da tarefa e transita por um campo mais amplo, com "pensamentos fora de lugar, percepções sem finalidade, reminiscências vagas, objetos desfocados e ideias fluidas, que advêm do mundo interior ou exterior".

Kastrup (2004) ressalta ser o distraído "alguém extremamente concentrado", com atenção em outro lugar. Zuin e Zuin (2011), com preocupações semelhantes afirmam que a “distração concentrada não permite fazer com que o olhar permaneça vinculado à palavra o tempo necessário para que a própria palavra seja tencionada, a ponto de remeter esse olhar para o 
vislumbre de outros significados". Nesse sentido, "apreender um conteúdo torna-se, mais do que nunca, condição fundamental para que ele possa ser de fato aprendido".

A subjetividade contemporânea, sob o olhar de Kastrup (2013), não sofre de falta de foco, mas de excesso de focalização. A atenção saltitante que ganha espaço nas práticas de estudo pode estar relacionada com os dispositivos usados pelos estudantes. "Parece tratar-se de uma captura que prende a atenção e a faz saltar entre focos distintos, impedindo que ela desvie"

Kastrup (2013) assevera que esse processo pode decorrer do "modo como as novas tecnologias, e em especial o computador-internet, capturam a atenção". Mas, para essa pesquisadora, as tecnologias podem auxiliar na "produção da política cognitiva curiosa e desejosa de saber", isso poderia favorecer a "a produção de novas relações entre estudantes e estudo". Seriam relações mais ligadas ao pensamento que às tarefas.

A pesquisadora destaca que as tecnologias não são em si positivas ou negativas, elas desafiam-nos a investigar os efeitos que produzem sobre a cognição e a subjetividade. Precisamos compreender que se elas estão a serviço da execução de tarefas predefinidas e da solução de problemas dados, não contribuem para mudanças de política cognitiva.

Sob uma perspectiva de mudança, sob o olhar de Kastrup (2005), o aprendizado assume a forma de um círculo, em que o movimento é o de reincidir, retornar, renovar, reinventar, reiterar, recomeçar. A "lógica circular do aprender aponta para o inacabamento do processo". O aprendizado torna-se uma sucessão de aprendizagens. "Ele é contínuo e permanente, não se fechando numa solução e não se totalizando em sua atualização, precisando por isso ser sempre reativado".

Segundo Kastrup (2005), a aprendizagem inventiva inclui a invenção de problemas e revela-se também como invenção de mundo. "Inventar é garimpar algo que restava escondido, oculto, mas que, após serem removidas as camadas históricas que o encobriam, revela-se como já estando lá".

Com as TIC as possibilidades de diferentes aprendizagens se ampliaram, nas palavras de Martin-Barbero (2011, p. 126) a "escola deixou de ser o único lugar de legitimação do saber, pois existe uma multiplicidade de saberes que circulam por outros canais, difusos e descentralizados". Com isso, a "diversificação e difusão do saber, fora da escola, é um dos desafios mais fortes que o mundo da comunicação apresenta ao sistema educacional".

Nesse sentido, Martin-Barbero (2011, p. 134) afirma que cabe à educação "ajudar a criar nos jovens uma mentalidade crítica, questionadora da inércia na qual as pessoas vivem". Esse 
mesmo autor assegura que a educação ganha significado "à medida que é capaz de desenvolver sujeitos autônomos. Ante uma sociedade que massifica estruturalmente, que tende a homogeneizar".

Martin-Barbero (2011, p. 134) identifica a possibilidade de sermos cidadãos como "diretamente proporcional ao desenvolvimento de sujeitos autônomos, isto é, de gente livre, tanto interiormente como em suas tomadas de posição". Pois, é necessário "gente que seja capaz de distanciar-se da arte que está na moda, dos livros que estão na moda; gente que pense com a própria cabeça, e não com as ideias que circulam ao seu redor".

Martin-Barbero (2011, p. 123) alerta que "nada pode prejudicar mais a educação do que nela introduzir modernizações tecnológicas sem antes mudar o modelo de comunicação que está por debaixo do sistema escolar". Ai reside importante desafio a ser superado, o "modelo predominante é vertical, autoritário na relação professor-aluno e linearmente sequencial no aprendizado. Enquanto permanecer a verticalidade na relação docente e de sequencialidade no modelo pedagógico, não haverá tecnologia capaz de tirar a escola do autismo em que vive. Por isso, é indispensável partir dos problemas de comunicação antes de falar de meios." (MARTIN-BARBERO, 2011, p. 123).

\section{ALGUMAS CONSIDERAÇÕES}

Esboçamos um desenho em que colocamos em relevo a arte de estudar, apontando o conhecimento acerca do conhecer como abertura de possibilidades para aprendizagens autodirigidas. Trazemos, também, olhares voltados à atenção em uma cultura que passeia por múltiplos focos, sem cuidadosas paradas. Completando, encontramos a escola persistindo em sua rota de cultuar o ensino, fundado na transmissão, com isso sua comunicação permanece verticalizada e o protagonismo é dos professores.

Procurando horizontes, entendemos que renovar a política cognitiva requer a superação da cultura que privilegia tarefas predefinidas e a solução de problemas dados, abrindo espaço para invenção de problemas e de mundos. Nesse processo, a escola seria um lugar de estudos e teria nos alunos protagonistas. 


\section{REFERÊNCIAS}

ALMEIDA, L. S. Facilitar a aprendizagem: ajudar aos alunos a aprender e a pensar. Psicologia Escolar e Educacional, vol. 6, n. 2, Campinas, dez. 2002. Disponível em <http://dx.doi.org/10.1590/S1413$85572002000200006>$. Acessado em 13 jan. 2012.

ALVARES, J. L.; KLIMENKO, O. Aprender cómo aprendo: la enseñanza de estrategias metacognitivas. Educación y Educadores, vol. 12, n. 2, 2009.

CHEVALLARD, Y., BOSCH, M. e GASCÓN, J. Estudar matemáticas: o elo perdido entre o ensino e a aprendizagem. Porto Alegre: Artemed, 2001.

COSENZA, R. M.; GUERRA, L. B. Neurociência e educação. Porto Alegre: Artmed, 2011.

FIGUEIREDO, F. J. C.; BARROS, J. O. Metacognição: tempo para ouvir a nós próprios. Disponível em <http://www.ipv.pt/millenium/17_ect10.htm>. Acesso em 13 mai. 2012.

JOU, G. I.; SPERB, T. M. A metacognição como estratégia reguladora da aprendizagem. Psicologia: Reflexão e Crítica, v. 19, n. 2. Porto Alegre, 2006. Disponível em http://dx.doi.org/10.1590/S010279722006000200003 . Acessado em 25 mar. 2012.

KASTRUP, V. A aprendizagem da atenção na cognição inventiva. Psicologia \& Sociedade, vol. 16, n. 3. Porto Alegre, set/dez. 2004. Disponível em: http://dx.doi.org/10.1590/S0102-71822004000300002. Acessado em 20 mai. 2013.

. Políticas cognitivas na formação do professor e o problema do devir-mestre. Educação \&

Sociedade, vol.26, n.93, Campinas, set./dez. 2005. Disponível em http://dx.doi.org/10.1590/S0101-73302005000400010. Acesso em 23 mar. 2013.

A aprendizagem da atenção na cognição inventiva. Psicologia \& Sociedade, vol.16, no.3, Porto Alegre, set. /dez. 2004. Disponível em http://dx.doi.org/10.1590/S010271822004000300002 . Acessado em 07 jul. 2013.

MARTIN-BARBERO, J. Desafios culturais: da comunicação à educomunicação. In: CITELLI, A. O.; COSTA, M. C. C (Orgs.) Educomunicação: construindo uma nova área de conhecimento. São Paulo: Paulinas, 2011.

RIBEIRO, C. Metacognição: um apoio ao processo de aprendizagem. Psicologia: Reflexão e Crítica, 2003, 16(1), pp. 109-116.

Rosário, P. e Almeida, L. (2005). Leituras construtivistas da aprendizagem. Em: G. Miranda;S. Bahia (Eds.). Psicologia da educação: temas de desenvolvimento, aprendizagem e ensino(141-165). Lisboa: Relógio D'água Editores.

SILVA, A. L.; SÁ, I. Saber estudar e estudar para saber. Porto: Porto Editora, 1993.

TURCKE, C. Sociedade excitada. Campinas-SP: Unicamp, 2010.

VEEN, W.; VRAKKING, B. Homo zappiens. Porto Alegre: Artmed, 2009. 
ZUIN, V. G; ZUIN, A. A. S. Professores, tecnologias digitais e a distração concentrada. Educar em Revista, n. 42, 2011. Disponível em: http://dx.doi.org/10.1590/S0104-40602011000500014. Acesso em 12 mai. 2012. 